\title{
Paper to Screen Migration and its Possible Impact on Photography
}

\author{
Julian Hawkins \\ 113 St James's Lane \\ London N10 3RJ, UK \\ jmh@julianmhawkins.co.uk
}

\begin{abstract}
“The revolution won't be televised, it will be streamed." This adaptation of paraphrasing Gil ScottHeron's was how Perelman (2014) to explain the importance of understanding the correct platform with which to disseminate your content. As a photographer who teaches undergraduate digital photography, I am highly aware of the rapidly changing face of my industry and how the certainties that existed earlier in my career have given way to an entirely new environment. It is my responsibility to endeavour to assist my students in understanding how to navigate this changing workplace and adapt to the differing demands that it expects. As screen based publishing supersedes paper, similar restructuring will happen as it did in the wake of Gutenberg with old professions fell away whilst new ones appeared. The same has been happening in the photographic industry over the past fifteen years. Photographers are no longer the suppliers of purely still images, they have moved into the realms of becoming content providers. Needing to be able to shoot stills as before yet also generate video footage, record audio (both ambient sound and specific interviews), edit and so forth.
\end{abstract}

Trying to make sense of what is currently a highly confused business landscape is something that photography educators need to address. Shirky (2009) proposes a positive outcome to the conundrum of what will replace the old model and that is, "Nothing will work, but everything might." And although it is now apparent that society no longer needs printed matter it still needs professional, ethical, committed photojournalists, writers and content creators to provide the raw material that will populate future media. While currently printed magazines such as ID remain as flagships for their electronic counterpart yet lose money.

The task I have set myself is to talk directly to leading practitioners and industry insiders in the hope of having a clearer understand of emerging technological trends, as well as the solutions that are being tested by creatives to adapt to the changes around us. At BBC Radio 1, they have moved a formerly aural media into the visual whilst still in essence being radio. This they achieved by engaging with their audience via YouTube and which the controller, Cooper (2014), described as "listen + watch + share." It is becoming that photographers need to understand not just the essentials of image capture but also those of image placement so that they can build themselves up and thus market themselves as a brand. Stephen Mayes observes this causing clients wanting to be associated with photographers who have high brand profile.

Photography. Paper. Screen. Migration. Newspapers. Magazines. Broadcasting. Multimedia. Media. Internet. Website. Online publishing. Photographers. Business. Technology. Apps. Mobile. Convergence. Stills. Video. Interactive. Paywall. Collaboration. Community. Practice. Followers. Partnership. Skills.

\section{INTRODUCTION}

The burgeoning of online publications is increasing the demand for content. Content of all types may be generated by professionals or amateurs yet online publications create an insatiable demand for it because, as can be observed, "Silence - visual or any other kind - is not something at which the Web excels" (Ritchin 2013, p. 13). Therefore, the pressure is on for suppliers to feed this growing demand with ever-greater quantity and frequency of material. Transformative change in publishing media is upon us and is in the process of altering the landscape of both media and photography in a manner that will make dramatic differences to the way in which photographers will be required to operate. The old fixed reference points; newspapers, magazines, etc., are fading away. 
There's a new arena and we do not yet know our way around. Mayes (2014) expresses satisfaction that we are moving away from the former patriarchal structure in which we are told what we are going to see but is skeptical that the mass does not have the right answer either. So he considers the balance to be very delicate and that we are in a time of evolution.

\section{NOTHING WILL WORK BUT EVERYTHING MIGHT}

This is not just impacting on print but also on radio and television and causing all the traditional media outlets to re-evaluate how they interface with digital technology. Some, such as radio, have already begun to adapt remarkably quickly. By using YouTube as a new outlet BBC Radio 1 has encouraged 3.5 million listeners to subscribe to its broadcasts. On this platform, they employ a combination of comedy, studio performances, DJ shows, live music events, interviews and more to engage with their audience. People can no longer be described solely as listeners. The online platform enables the listener/follower to change their position within the overall interaction process so that they consume radio yet view and interact with it at the same time. An exchange is created thereby discarding previous notions of what had constituted radio as a medium and the listener becomes a participant. The station's migration to a digital, web based platform causes radio to become visual and thus there is a demand for visuals and interactivity whilst still remaining aural. Image content to support radio broadcasting is now essential thereby creating new job opportunities for visual content creators such as photographers. Cooper (2014), the station's controller, defined their new engagement with their audience as, "listen + watch + share". Or radio reinventing itself for both web and mobile devices.

A similar process is starting to occur at the BBC 3 television channel. Initially launched as another linear channel to complement the rest of the BBC stable it became an online only broadcaster in 2016. It is worthwhile noting that since their move to a digital only platform they are commissioning stills photography to augment their documentary output. Kelly (2017) is a contemporary documentary photographer receiving commissions from them to develop and shoot several stills assignments that are used to support programme content.

Meanwhile changes are rapidly taking place at newspapers and magazines. The Guardian now has offices in London, New York and Sydney. As Tooth (2015) their Head of Photography explained "A newspaper website like The Guardian now is a
24/7 broadcaster". This also brings with it a vastly increased demand for content and in turn opportunities for those willing and capable of creating that material. There are two principle issues at play here; the inevitability of technology drives the overall process forward whilst the generational aspect holds it back. Esterson (2014) elaborated on why the upheaval that is taking place is causing so many challenges to all practitioners by drawing a comparison with the immediate aftermath of Gutenberg's invention of moveable type. "Because print is a mature medium everyone finds it hard to consider working in different ways. Digital publishing changes almost daily and is advancing very rapidly". He went on to add that "...those [currently] in charge are the final generation who grew up with printed things". Esterson's comments reflect Eisenstein (1980, p. 25) where she compares Gutenberg as heralding the initiation of a "communication revolution" and Man (2002) who pointed out that the spread of Gutenberg's invention led to revolutions in literacy and science and also heralded the great political and social upheaval that was the reformation.

An equivalent commercial and cultural restructuring is already happening as screen based publishing replaces print. In the wake of Gutenberg old professions fell away (scribes) whilst new ones appeared (printers, block-makers) and similar realignments are occurring as screen based publishing supersedes paper. Shirky (2009) points out that this period of change was chaotic, "that's what revolutions are like. The old stuff gets broken faster than the new stuff is put in its place". Shirky takes a radical but stimulating position here by insisting that when we ask to be told what will replace our former, stable landscape we, "are demanding to be lied to". When confronted by the simple economics that the web makes content dissemination easier, quicker, simpler and more pluralistic, our insecurities demand that the old certainties are transferred into the new business environment. He does propose a positive outcome to the conundrum of what will replace the old model and that is, "Nothing will work, but everything might". And although it's now apparent that society no longer needs printed matter in the way it once did it still needs professional, ethical, committed photographers, writers and content creators to provide the raw material that will populate future media. It is therefore the responsibility of committed professionals to explore every avenue with the aim of finding a new, viable model. This should encompass how to work, research, shoot, source clients, market, brand, position, collaborate and monetise our skills in this new business world. Innovation must be the way forward. I will argue here that freelance stills photographers are ideally placed to capitalize on the opportunities that are currently arising. 


\subsection{Adapting to the Change}

"The revolution won't be televised, it will be streamed". This adaptation of Gil Scott-Heron's words was used (Perelman 2014) to explain BuzzFeed's contention that prior to successfully engaging with screen-based media it is imperative to understand the platform that you will use to disseminate your content. Just uploading to a website in itself is not sufficient, it needs a solid understanding of social media portals in order to select the most appropriate to support and draw traffic to your material. His company's research has identified three main players; Twitter for instant but short-lived material, Facebook for sharing material that has value over a few days and finally Pinterest that will be steady and longer lasting. Bush (2017) takes Perelman's argument further by emphasizing the need to learn how to exist as a photographer online. He explains that to both survive and thrive on the web and therefore on screen it is essential that photographers understand, "...how images are prioritized or discriminated against by algorithms" on the different social media platforms. In addition, he stresses the necessity to know, "How to construct projects that may only exist online". With this in mind, it is clearly just as important that photographers give as much attention to learning about the mechanics of the web as they do to the mechanics of the camera and understanding the process of image capture.

The combination of digital photography together with traditional print media migrating to the Internet has ushered in great change to the way that professional photographers are required to operate. The new working practices are legion and it's, "...no good reminiscing about how things were" (Bush 2017) but instead concentrate on finding creative solutions that allow you to work within the economic ramifications of digital imaging. Vice is an interesting example of a business model that is only able to exist because of the new digital world. Hawker (2015) explains it thus, "The whole model of photographers coming to an art director and being sent to...capture images or a story... is just not there anymore". He describes Vice's successful model as buying in content, brand this incoming material, disseminate it via YouTube and sell advertising against it.

Tooth (2015) sums up what he sees as happening as us moving from a two-dimensional to a threedimensional world. He sees migration to screen as requiring stills photographers to adopt the skills of broadcasters. He takes this further by explaining that photographers require greater flexibility in their approach and a willingness to be generating personal work as well as taking on commissions. His advice is that "you probably want to go and shoot stills...video and...some audio track as well.
So when someone says, "We'd like to make some multimedia content from your shoot" you're able to provide all the elements". He went on to stress that in his field one of the most highly sought after professionals is now a photographer who can author and edit a whole film.

Photography is now at a juncture like that which occurred at the time of Gutenberg. By the nature of the way in which photographers have always worked they bring an innate openness to an interdisciplinary approach that is well suited to the changing face of the media industry. For the photographer, converging digital technology in DSLR cameras, promises new potential for interdisciplinary practice and clients are expecting this. James (2014) drew attention to this by saying, “... we're finding ... [clients] are wanting photographers to shoot [stills] and film and sound and all for no extra money. To use for a multimedia afterwards." This emphasizes how different disciplines are doing more than overlapping, they are interweaving. Creative director Syed (2014) took this up by explaining how he sees a convergence taking place between still and moving image which is generating a space in between these formally stand alone disciplines that provides possibility to reinvent what photography has been up until now. Gardener from Wired (2014) took this a stage further by stating that when commissioning he will only hire photographers who can shoot stills as well as film and can also edit. An advertising photographer (Smith 2014) explained that he undertakes all his shoots with the expectation that he will be required to shoot film (video) once the stills have been completed. The recent New York Times Lens Blog conversation between Estrin and Davis (2017) highlights the new opportunities that these changes offer. They reflect that "Today you can bypass the gatekeepers and publish directly to your own audience" and this in itself is both liberating and stimulating.

Market forces together with new technology are driving the changes forward yet there is also a generational split amongst professionals. Many older and more established practitioners hanker after an ideal past of high fees and job security and there is resistance from many different quarters. Professionals in all sectors that generate content feel pressurised both by technological changes plus the arrival of practitioners from other disciplines who are seen to be encroaching on their territory. Esterson (2014) summed this up by saying that, "All those professional barriers are irrelevant. As everything becomes digital all of the old job descriptions no longer mean anything." By contrast the younger generation appear more open to navigating the changes and developing new business models that allow them to monetize their craft. Estrin's interview with Winslow (2017) reflects 
on declining fees and the expectation that you will need to do more for the same money but also accepts that the industry is in flux and, "now it's evolving into whatever the next thing it is." In contrast the opposing view representing the younger generation is (Davis 2017) that "It was never an easy field" and they recognise that "this job is supposed to be hard" and in all honesty those particular challenges of working in the media are part of its great attraction.

\subsection{New Economic Model}

It's apparent that a new economic model has to be found and the New York Times (NYT) is having more success at building its digital subscriber base than any other publication. Snyder (2017) has examined the NYT's ambitious strategy that aims to give readers such a valuable product "that a subscription becomes indispensable to the lives of its existing subscribers and more attractive to future ones". The pay wall has been its biggest business success to date, five years from launching "more than 1.5 million people pay more than $\$ 200$ million every year for a subscription." Their goal is to generate sufficient digital revenue by 2020 "to fund the Times' global news-gathering operation with or without a print edition." The Times' approach has been to invest heavily in journalism as its core offering whilst "continuously adding new online services and features." The newspaper realises that journalism and storytelling lie at its heart and therefore there is a commitment to place "greater emphasis on visuals, greater variety of formats and voices". The development and expansion of its offerings that encompass everything from cooking to VR creates demand for more content from those who can create it and so has to be beneficial to photographers.

National Geographic can also be seen as successfully adopting and integrating interactivity in its electronic form. Gardener (2014) regards their approach, "as intent on offering the user the chance to read or listen or look either separately or in any combination" and thereby heightening the interaction between publication and reader. Accurately captioned still images continue to have a place, able to stand-alone or become part of a slide show. At the same time, embedded video and graphics further enhance the features and all lead to a radically different user experience.

The requirement that photographers adopt new skillsets to fulfill the needs of the emerging online platforms first came to prominence with projects such as Snowfall and Basetrack and has since continued apace. De Vigal (2013) has noted that 'Snow Fall is a prime example of users' deep engagement and cinematic inter-actives on a linear narrative" and that it "demonstrates one approach to evolving this story form".

Basetrack was a social media project operated by embedded photographers in Afghanistan; it connected US service personnel with their families and achieved this by interfacing via Facebook and Google Maps. Ritchin (2013, p. 63) considers it, "an example of photographers joining forces to make a larger statement and intent on involving their audience in the discussion". Apart from learning new techniques there is a need for openness to collaborate with other professionals as outlined in the pioneering work of Etienne Wenger and Jean Lave. Collaboration can lead to the birth of a community of practice, a concept described by Wenger and Lave (2009) as, "groups of people who share a concern or a passion for something they do and learn how to do it better as they interact regularly". Indeed, learning is built into the fabric of a community of practice due to the necessity for interaction between its members and as "Sharing tacit knowledge requires interaction and informal learning processes such as storytelling..." (Wenger et al. 2002, p. 9) photographers are ideally placed to take advantage of it.

\subsection{Changed Business Model}

An undeniable consequence of all the changes is that the method of engagement between photographer and their potential clients has altered. Mobile apps such as Instagram offer the capability to develop a brand identity that clients will want to associate with. Odueyungbo is a contemporary photographer who has rewritten the business model by his early adoption and consistent exploitation of the Instagram platform. With over $90 \mathrm{k}$ followers he has assiduously developed a brand identity which mean that clients come to him rather than the other way round. Taking inspiration from Depardon's Correspondance New-Yorkaise (1981), he (Odueyungbo 2017) would post images in his specific style and caption with a quotation, "to make people think more about the image...l wanted them to spend more time on my image". In this way he made his images intrinsically personal in a manner described by Ritchin (1999, p. 107) "He recounts his experiences through the openly acknowledged subjective feelings of a human being, not the traditionally unsentimental witness". Odueyungbo's Instagram strategy has succeeded in building him a roster of high profile clients who, once they know him, depend on the traditional business qualities of professionalism and reliability that he offers. 
Opportunities are opening whereby photographers and advocacy groups can form long-term beneficial relationships. Ritchin (2013, p. 105) references Marcus Bleasdales's collaboration with Human Rights Watch then quotes Stephen Mayes (p. 106) in his role as director of the VII agency. Mayes considers a market where clients will want to become associated with photographers who have a high brand profile, "While the value of an individual image is declining, the value of the work is still there. Today the value resides with the photographer. He or she has become the brand." This extends beyond the individuals set style and sector, which was previously known just within that small circle (advertising, fashion, etc.) and opens out onto the web so developing mass awareness using social media. Odueyungbo is successfully monetizing Instagram in the way that Mayes (2012) anticipated, "they can be approached by brands..." or "...they are approaching the brand and offering to introduce their following to the world."

There is still considerable controversy about the use of mobile apps such as Instagram but this is declining as image quality improves and clients commission work shot in this way. Following Hurricane Sandy in 2012 the only way for Time Light Box to document the storms impact was to have their photographers post via Instagram. Guttenfelder (2016) passionately debated his adoption of Instagram at Visa Pour L'Image and described how he uses "it as a way to take my audience into the field with me." With one million followers across three accounts and $50 \%$ of his National Geographic commissions in the previous twelve months shot with a mobile phone he has mastered this technology.

\section{CONCLUSION}

The consequence of the changes taking place has been a democratisation of content generation but at the same time a more rigorous practice is being demanded of professional. Coomes (2016) from the BBC News website regards photographers as needing to provide something different. "Just a picture is not enough" however multimedia "shot in the way a stills photographer would shoot" is highly sought after.

The new technical and collaborative skills required are fully interchangeable with whichever sector of the industry you choose to work in. Having this knowledge enables you to take advantage of the opportunities arising as a result of the migration from paper to screen. To truly succeed will require great self-belief in what you are doing so we should look to the new generation of photographers for inspiration as to how to approach the changing marketplace and successfully monitise their skills.

However the scope of what is required is now greater. During an online lecture, Mayes (2014) counseled that, "The boundaries between what was once a photographer have shifted. The notion of partnerships has to be part of the way forward, if not the workload will become crushing."

\section{REFERENCES}

Bleasdale, M. [Internet]

http://www.marcusbleasdale.com (accessed 5 April 2014).

Bush, L. (2017) Interview with the author. London, 7 February. [Lewis Bush is a photographer, writer and editor of Disphotic.] http://www.disphotic.com (accessed 24 May 2017).

Coomes, P. (2015) Interview with the author. London, 15 December. [Phil Coomes is the Picture Editor at BBC News website.]

Cooper, B. (2014) Young People Revolting - How to survive the changing demands of the heads down generation. \#RethinkMedia Conference, Birmingham, UK.

Davis, L. (2017) Photojournalism's Uncertain Future? She Begs to Differ. [Internet.] New York Times, 18 February.

https://lens.blogs.nytimes.com/2017/02/18/photojou rnalisms-uncertain-future-she-begs-to-differ

(accessed 23 February 2017).

Depardon, R. and Bergala, A. (1981) Correspondance New-Yorkaise - Les Absences du Photographe. Libération/Editions de L'Etoile.

De Vigal, A. (2013) Smart Readers Are Too Distracted To Dig Smart Content. [Internet] Wired. http://www.wired.com/2013/04/raw-meet-andrewdevigal/ (accessed 15 January 2014).

Eisenstein, E. (1980) The Printing Press as an Agent of Change. Cambridge University Press, Cambridge.

Esterson, S. (2014) Interview with the author. London, 13 March. [Simon Esterson is an art director and typographer.]

Gardener, K. (2013) Interview with the author. London, 2 December. [Kieran Gardener is an art director and tablet designer at Wired).

Guttenfelder, D. (2016) Meet the Photographers. Visa Pour L'Image, Perpignan, France. 
James, P. (2014) Interview with the author. London, 10 March. [Paula James is the Archive Manager at Panos Pictures.]

Kelly, J. (2017) Interview with the author. London, 12 March. [Jessica Kelly is a freelance documentary photographer.]

http://www.jessicakellyphotography.com (accessed 24 May 2017).

MAPJD Lecture Archive (2013) Ed Kashi. London: 24 October.

MAPJD Lecture Archive (2014) Stephen Mayes. London: 14 January.

Man, J. (2002) The Gutenberg Revolution. Headline Review, London.

Mayes, S. (2012) Photographs Are No Longer Things, They're Experiences. [Internet] Wired http://www.wired.com/2012/11/stephen-mayes-viiphotography/all/ (accessed 15 January 2014).

Mayes, S. (2014) Photo Expert Stephen Mayes On Photography's Future. [Internet] Imagesource http://www.imagesource.com/blog/stephen-mayeson-photography/ (accessed 29 January 2014).

Odueyungbo, O. [Internet.]

http://instagram.com/greatarsenal\# (accessed 2 April 2014).

Odueyungbo, O. (2017) Interview with the author. London, 5 March. [Ope Odueyungbo is a freelance photographer and Instagramer.]

http://www.opeophotography.com (accessed 24 May 2017).

Perelman, J. (2014) The Future of Media and the New Business Model. \#RethinkMedia Conference, Birmingham, UK.
Ritchin, F. (1999) In Our Own Image. Aperture Foundation, New York.

Ritchin, F. (2013) Bending The Frame. Aperture Foundation, New York.

Shirky, C. (2009) Newspapers and Thinking the Unthinkable. [Internet.]

http://www.shirky.com/weblog/2009/03/newspapers -and-thinking-the-unthinkable/ (accessed 12 March 2014).

Smith, C F. (2014) Interview with the author. London, 3 March. [Chris Frazer Smith is a freelance advertising photographer.] http://www.chrisfrazersmith.com (accessed 24 May 2017).

Snyder, G. (2017) Keeping up with the Times. [Internet.]

https://www.wired.com/2017/02/new-york-timesdigital-journalism (accessed 22 February 2017).

Syed, S. (2014) Interview with the author. New York, 28 February. [Sam Syed is a freelance designer and creative director for web and print.]

Tooth, R. (2015) Interview with the author. London, 22 January. [Roger Tooth is Head of Photography at The Guardian Media Group).

Wenger, E. (2009) Communities of Practice. [Internet.] http://infed.org/mobi/jean-lave-etiennewenger-and-communities-of-practice/ (accessed 6 April 2014).

Wenger, E, McDermott, R, and Snyder, W. (2002) Cultivating Communities of Practice. Harvard Business School Press, Boston.

Winslow, D. R. (2017) The Uncertain Future of Photojournalism. [Internet.] New York Times. https://lens.blogs.nytimes.com/2017/02/15/theuncertain-future-of-photojournalism (accessed 19 February 2017). 